\title{
Identifikasi Sektor Ekonomi Unggulan di Daerah Tangkapan Air Danau Rawa Pening
}

\section{Sigit Andy Cahyono ${ }^{1}$}

Balai Penelitian dan Pengembangan Teknologi Pengelolaan Daerah Aliran Sungai, Indonesia

Faiqotul Falah

Balai Penelitian dan Pengembangan Teknologi Pengelolaan Daerah Aliran Sungai, Indonesia

\section{S. Agung Sri Raharjo}

Balai Penelitian dan Pengembangan Teknologi Pengelolaan Daerah Aliran Sungai, Indonesia

Artikel Masuk : 8 Mei 2019

Artikel Diterima : 20 April 2020

Tersedia Online : 30 April 2020

\begin{abstract}
Abstrak: Danau Rawa Pening merupakan salah satu danau prioritas yang menghadapi persoalan eutrofikasi dan sedimentasi cukup parah. Pertanian masyarakat menjadi salah satu yang diduga menjadi sumber masalah di Danau Rawa Pening, padahal kesejahteraan masyarakat menjadi salah satu kebijakan pemerintah. Oleh karena itu, pengembangan sektor ekonomi di Daerah Tangkapan Air (DTA) dan sempadan Danau Rawa Pening harus memiliki keunggulan, namun informasi atas hal ini masih diabaikan dan terbatas. Penelitian ini bertujuan untuk menganalisis sektor ekonomi unggulan di daerah tangkapan air Danau Rawa Pening. Penelitian menggunakan metode Tipologi Klassen untuk mengetahui pola dan struktur ekonomi serta metode Location Quotient dalam menentukan sektor ekonomi yang memiliki keunggulan komparatif di setiap kecamatan yang berada di daerah tangkapan air danau Rawa Pening dan analisis kontribusi sektoral. Data yang dipergunakan merupakan data sekunder dan pengamatan lapangan. Hasil penelitian menunjukkan bahwa Kecamatan Bawen merupakan daerah maju tetapi tertekan, mengandalkan sektor industri pengolahan. Kecamatan yang maju pesat (Tuntang, Jambu, Sumowono, dan Ambarawa) mengandalkan semua sektor ekonomi. Kecamatan yang tertinggal (Getasan dan Banyubiru) mengandalkan sektor primer. Sektor unggulan setiap kecamatan berbeda tergantung pada sumber daya dan keunggulan komparatifnya. Sektor ekonomi unggulan berkontribusi relatif signifikan pada perkembangan perekonomian di DTA Danau Rawa Pening. Pengembangan sektor ekonomi akan lebih baik diarahkan pada sektor ekonomi unggulan sehingga dapat menarik sektor yang bukan basis terutama dalam keterbatasan sumber daya dan alokasi anggaran pembangunan. Selain itu, analisis location quotient dapat digunakan untuk analisis wilayah dengan batas alamiah seperti daerah tangkapan air atau daerah aliran sungai.
\end{abstract}

Kata Kunci: daerah tangkapan air; location quotient; keunggulan komparatif

\footnotetext{
${ }^{1}$ Korespondensi Penulis: Balai Penelitian dan Pengembangan Teknologi Pengelolaan Daerah Aliran Sungai Email: sandycahyono@yahoo.com
} 


\title{
37 Identifikasi Sektor Ekonomi Unggulan di Daerah Tangkapan Air Danau Rawa Pening
}

\begin{abstract}
Rawa Pening Lake is one of the priority lakes facing severe eutrophication and sedimentation problems. Agriculture is one of the problems in Rawa Pening Lake, even though community welfare is the government's policies. For this reason, the development of the economic sector in Rawa Pening catchment area must have advantages, yet information on this is still neglected and limited. The study aims to analyze the leading economic sectors in the Rawa Pening catchment area. The study used the Klassen Typology method to determine the pattern and structure of the economy and the Location Quotient method in determining the economic sector that has a comparative advantage in each sub-district and analysis of sectoral contributions. The data used is secondary data and field observations. The results showed that Bawen Subdistrict was a developed but depressed area, relying on the manufacturing industry sector. Rapidly developing districs (Tuntang, Jambu, Sumowono, and Ambarawa) rely on all economic sectors. The lagging districts (Getasan and Banyubiru) relly on the primary sector. Leading sectors of each district differ depending on resources and comparative advantage. Leading economic sector contribute relatively significantly to economic development in the lake Rawa Pening catchment. The development of the economic sector will be better directed to leading economic sector so that it can attract sector that are not base, especially in the limited resources and allocation of development budgets. In addition, Location Quotient analysis can be used for analysis of areas with natural boundaries such as catchments or watersheds.
\end{abstract}

Keywords: catchment area; comparative advantage; location quotient

\section{Pendahuluan}

Danau Rawa Pening merupakan salah satu bagian dari Daerah Aliran Sungai (DAS) Tuntang dan merupakan inlet bagi enam belas aliran Sungai Tuntang (Pusat Limnologi LIPI, 2011). Luas permukaan Danau Rawa Pening mencapai 2.667 ha, dengan luas genangan danau mencapai 1.850,10 ha pada musim kemarau. Kedalaman danau 0,35-10 m, sedangkan rata-rata kedalamannya 2,17 m. Adapun luas Daerah Tangkapan Air (DTA) sebesar 250,79 km² atau 25.079 hektar (Pusat Bendung Kementerian Pekerjaan Umum, 2018).

Daerah Tangkapan Air (DTA) merupakan kawasan yang berfungsi sebagai penadah air dengan fungsi hidrologisnya dalam menjaga ketersediaan air (Purboseno, 2013). Danau Rawa Pening merupakan salah satu danau prioritas nasional (Kementerian Lingkungan Hidup, 2010) yang penting artinya secara ekonomi, sosial budaya dan lingkungan. Secara ekonomi Danau Rawa Pening berfungsi utama sebagai Pusat Listrik Tenaga Air (PLTA) yang memasok listrik Jawa Bali, irigasi, pertanian, perikanan darat, wisata, dan air minum (Gerhard \& Susilowati, 2013; Soeprobowati, 2011, 2012). Secara sosial budaya terdapat kegiatan resik-resik rowo, sedekah rowo, (Cristianawati, 2017; Ridwan, 2013; Seftyono, 2014) dan merupakan landmark Jawa tengah (Bappeda Provinsi Jawa Tengah, 2005; Partomo, Mangkuprawira, Hubeis, \& Adrianto, 2011). Secara lingkungan, Rawa Pening merupakan reservoir alami, pencegah banjir, penyedia hara, dan sebagainya (Partomo et al., 2011). DTA merupakan hulu dari sungai-sungai yang mengalir ke Danau Rawa Pening, sehingga pola pemanfaatan lahan dan aktivitas ekonominya akan memengaruhi kualitas, kuantitas dan kontinuitas air yang masuk kedalam danau. Danau Rawa Pening merupakan salah satu danau prioritas yang menghadapi persoalan eutrofikasi, penutupan eceng gondok (Eicchornia crassipes), dan sedimentasi cukup parah (Girsang et al., 2019; Hidayati et al., 2018) serta ketersediaan air (Nugroho, 2017) dan kualitasnya (Aida \& Utomo, 2017; Heriza, Sukmono, \& Bashit, 2018; Piranti, Rahayu, \& Waluyo, 2018). Meskipun eceng gondok dianggap sumber masalah, tetapi ada masyarakat yang menganggap eceng gondok bermanfaat terutama untuk peningkatan pendapatan (Ningsih et al., 2019). Upaya penanganan Rawa Pening sudah banyak dilakukan salah satunya dengan Gerakan 
Penyelamatan Danau (Germadan) (Raharjo, Falah, \& Cahyono, 2019; Soeprobowati, 2015) maupun manajemen kolaboratif (Nadjib, 2016). Pertanian masyarakat menjadi salah satu yang disinyalir menjadi sumber masalah di Danau Rawa Pening karena pembukaan lahan dan pertanian yang tidak bijak meningkatkan erosi sedimentasi di Danau Rawa Pening (Ardi \& Rahayu, 2013; Haryani, 2010) padahal kesejahteraan masyarakat menjadi salah satu kebijakan pemerintah. Peningkatan kesejahteraan masyarakat memerlukan efisiensi dalam pengelolaan sumber daya, sehingga sumber daya dapat dialokasikan dengan tepat. Langkah awal untuk pengelolaan sumber daya yang efisien adalah penentuan sektor unggulan yang diusahakan sehingga diperoleh keunggulan komparatif. Oleh karena itu, pengembangan sektor ekonomi di DTA dan sempadan Danau Rawa Pening harus dipilih yang memiliki keunggulan, namun informasi atas hal ini masih diabaikan dan terbatas.

Suatu daerah dapat cepat tumbuh apabila memiliki sektor ekonomi yang mampu mengakselerasi pembangunan dan sektor-sektor ekonomi lainnya. Penentuan sektor ekonomi unggulan dalam pembangunan daerah sangat penting bagi suatu daerah agar sumber daya yang tersedia dapat dialokasikan dengan tepat. Tumbuhnya sektor ekonomi unggulan di suatu daerah diyakini oleh Restiatun (2009) akan membuat tumbuh dan berkembangnya sektor lain dan daerah sekitarnya. Daerah pengembangan sektor ekonomi unggulan tersebut akan membuat penyerapan tenaga kerja dan sumber daya dari daerah sekitar dan diekspornya produk serta jasa dari daerah tersebut.

Sektor ekonomi unggulan dapat diidentifikasi dengan merujuk kepada teori basis. Teori basis ekspor murni dikembangkan pertama kali oleh Tiebout (1956). Teori basis ekonomi berpandangan bahwa laju pertumbuhan ekonomi suatu wilayah ditentukan oleh besarnya peningkatan ekspor dari wilayah tersebut. Teori ini mengelompokkan kegiatan ekonomi dalam kegiatan basis dan nonbasis. Kegiatan basis adalah semua kegiatan baik penghasil produk maupun penyedia jasa yang mendatangkan uang dari luar wilayah, sedangkan kegiatan nonbasis adalah untuk memenuhi kebutuhan konsumsi lokal. Oleh karena itu, permintaan sektor nonbasis ini sangat dipengaruhi oleh tingkat kenaikan pendapatan masyarakat setempat. Kondisi tersebut membuat sektor nonbasis terikat terhadap kondisi ekonomi setempat dan tidak bisa berkembang melebihi pertumbuhan ekonomi wilayah. Atas dasar asumsi tersebut, maka satu-satunya sektor yang bisa meningkatkan perekonomian wilayah melebihi pertumbuhan alamiah adalah sektor basis (Tarigan, 2004). Asumsi tersebut membuat suatu daerah akan mempunyai sektor unggulan apabila daerah tersebut dapat memenangkan persaingan pada sektor yang sama dengan daerah lain sehingga dapat menghasilkan ekspor. Analisis ini sering disebut analisis Location Quotient (Berawi, Zagloel, Miraj, \& Mulyanto, 2017). Location Quotient cukup mudah (Guimarães, Figueiredo, \& Woodward, 2009) dan telah banyak dilakukan. Beberapa peneliti fokus pada penggunaan metode ekonomi wilayah dengan menggunakan batasan wilayah administratif baik pada skala nasional, provinsi, kabupaten dan kecamatan (Bangun, 2018; Billings \& Johnson, 2012; Darwin, 2017; Erna, Harisudin, \& Rahayu, 2017; Faijah \& Wahbi, 2017; Farida, 2017; Fikri \& Fafurida, 2018; Hadi, Suciati, \& Asnawi, 2018; Ibrahim, 2018; Iyan, 2014; Listyana, 2016; Mustofa \& Haryati, 2018; Nindhitya, 2013; Ningrum, 2017; Nuraini \& Setiartiti, 2017; Pinem, 2016; Riyardi, 2013; Rustiadi, 2018; Sari, 2010; Setianto \& Susilowati, 2014; Sudarsono, Fitriadi, \& Nurjanana, 2018; Suhartono, 2011; Susanto, 2014; Kesuma \& Utama, 2015). Namun, dari penelitian tersebut, hampir tidak ada yang menggunakan analisis ekonomi wilayah pada batasan alami suatu wilayah misalnya daerah tangkapan air atau daerah aliran sungai, kecuali pada penelitian Cahyono \& Wijaya (2014). Namun, analisis ekonomi wilayah pada daerah tangkapan air untuk danau belum ada yang melakukannya. Penggunaaan batasan alamiah bukan administratif dapat menunjukkan interaksi penggunaan sumber daya dengan aktivitas ekonomi termasuk dampaknya misalnya erosi, dan limbah aktivitas ekonomi yang terbawa aliran air mengikuti batas alamiahnya. Selain itu, kawasan Rawa Pening belum pernah dilakukan identifikasi 


\section{Identifikasi Sektor Ekonomi Unggulan di Daerah Tangkapan Air Danau Rawa Pening}

sektor ekonomi unggulan yang penting bagi perencanaan pembangunan kawasan Rawa Pening. Sebagian besar kajian dan studi di Danau Rawa Pening berfokus pada masalah fisik, spasial dan biologi tetapi kajian ekonominya masih sangat terbatas. Informasi sektor ekonomi unggulan diperlukan untuk menentukan prioritas pembangunan yang harus didahulukan dalam keterbatasan sumber daya dan alokasi anggaran pembangunan. Oleh karena itu, penelitian ini difokuskan pada identifikasi sektor ekonomi unggulan di daerah tangkapan air Danau Rawa Pening. Penelitian ini bertujuan untuk menganalisis sektor ekonomi unggulan di daerah tangkapan air Danau Rawa Pening..

\section{Metode Penelitian}

Penelitian ini dilakukan di Sub DAS Danau Rawa Pening. Topografi Danau Rawa Pening merupakan tanah datar dikelilingi tiga gunung yaitu Gunung Merbabu, Telomoyo dan Ungaran (Kementerian Lingkungan Hidup, 2011; Pusat Limnologi LIPI, 2011). Secara administratif Danau Rawa Pening berada di Kabupaten Semarang dan daerah tangkapan airnya sebagian besar berada di Kabupaten Semarang dan sebagian kecil berada di Kota Salatiga. (Direktorat Jenderal Sumber Daya Air Balai Besar Wilayah Sungai Pemali Juana, 2016).

Data yang dipergunakan pada penelitian ini merupakan data primer dan sekunder. Data primer ditentukan secara purposive atau judgemental sampling dengan kriteria pihak yang mengetahui dan terlibat dalam pengelolaan dan pemanfaatan Danau Rawa Pening. Data primer tersebut diperoleh melalui wawancara kepada lima belas orang informan kunci (key informan) seperti dari Badan Perencanaan Pembangunan, Penelitian dan Pengembangan Daerah (Bappeda) Provinsi Jawa Tengah (2 orang), Balai Besar Wilayah Sungai (BBWS) Pemali Juana (2 orang), Balai Pengelolaan Daerah Aliran Sungai (BPDAS) (2 orang), Dinas Pengelolaan Sumber Daya Air (PSDA) Provinsi Jawa Tengah (2 orang), Pemerintah Provinsi Jawa Tengah (1 orang), PLTA Jelok Timo (2 orang), PT Sarana Tirta Ungaran (1 orang), Universitas Diponegoro (1 orang) dan lainnya (2 orang). Selain itu, data primer juga diperoleh melalui observasi lapangan di DTA Danau Rawa Pening dan diskusi mendalam dengan lima orang. Data sekunder berasal dari kabupaten/kota yang berada di Sub DAS Rawa Pening. Data yang dipergunakan dalam penelitian ini meliputi Produk Domestik Regional Bruto (PDRB) harga konstan dan berlaku per kecamatan pada daerah yang masuk dalam DTA Rawa Pening. Kecamatan yang masuk dalam DTA Rawa Pening antara lain Bawen, Tuntang, Getasan, Banyubiru, Jambu, Sumowono, dan Ambarawa. Periode pengamatan penelitian untuk data PDRB yang digunakan mulai dari tahun 2008 sampai dengan 2012. Periode ini dipilih karena hanya pada periode tersebut data tersedia dengan cukup baik sampai tingkat kecamatan, setelah tahun 2012 pihak Badan Pusat Statistik (BPS) tidak mempublikasikan data PDRB tingkat kecamatan di lokasi kajian. Sumber data yang digunakan dalam penelitian ini berasal dari publikasi Badan Pusat Statistik (BPS) dan instansi lain yang relevan. Pengolahan data dalam penelitian ini menggunakan teori basis ekonomi.

\section{Tipologi Klassen}

Pola dan struktur pertumbuhan ekonomi suatu wilayah kecamatan di Sub DAS Danau Rawa Pening dihitung dengan menggunakan Tipologi Klassen. Tipologi Klassen dapat dipergunakan untuk memetakan atau menggolongkan kemajuan daerah berdasarkan pertumbuhan ekonomi dan pendapatan per kapita. Berdasarkan pada uraian tersebut, wilayah kecamatan dapat diklasifikasikan menjadi (1) kecamatan yang cepat maju dan cepat tumbuh (high growth and high income); (2) kecamatan yang maju tapi tertekan (high income but low growth); (3) kecamatan yang berkembang cepat (high growth but low 
income); dan (4) kecamatan yang tertinggal (low growth and low income). Secara skematis dapat dideskripsikan melalui Tabel 1.

Tabel 1. Matrik Klasifikasi Kecamatan dalam Sub DAS Danau Rawa Pening Menurut Tipologi Klassen

\begin{tabular}{cll}
\hline Tingkat Pertumbuhan & \multicolumn{2}{c}{ PDRB per kapita (Y) } \\
\cline { 2 - 3 }$(\mathbf{R})$ & \multicolumn{1}{c}{ Yi $>\mathbf{Y}$} & \multicolumn{1}{c}{$\mathbf{Y}<\mathbf{Y}$} \\
\hline $\mathrm{Ri}>\mathrm{R}$ & Kecamatan maju dan cepat tumbuh & Kecamatan berkembang cepat \\
$\mathrm{Ri}<\mathrm{R}$ & Kecamatan maju tapi tertekan & Kecamatan tertinggal \\
\hline Keterangan: $\mathrm{Ri}=$ tingkat pertumbuhan PDRB kecamatan; $\mathrm{R}=$ tingkat pertumbuhan PDRB DAS; Yi $=$ \\
PDRB per kapita kecamatan; $\mathrm{Y}=$ PDRB per kapita di DAS.
\end{tabular}

\section{Location Quotient}

Penentuan sektor ekonomi unggulan di DTA Rawa Pening menggunakan analisis ekonomi basis yaitu Location Quotient (LQ). Analisis LQ dapat digunakan untuk mengetahui potensi aktivitas ekonomi yang merupakan sektor basis dan bukan sektor basis. Analisis tersebut merupakan perbandingan relatif antara kemampuan sektor yang sama pada daerah yang lebih luas dalam suatu wilayah (Rustiadi, 2018). Dalam penelitian ini, LQ dipakai untuk menentukan sektor unggulan dengan pendekatan nilai tambah (PDRB) kecamatan dalam DTA Rawa Pening dan PDRB dalam suatu DTA Rawa Pening, dengan menggunakan persamaan (1), sebagai berikut:

$$
L Q=\frac{p i / p t}{P i / P t}
$$

Keterangan: $\mathrm{pi}=$ nilai $\operatorname{PDRB}$ sektor $\mathrm{i}$ di kecamatan $\mathrm{j} ; \mathrm{pt}=$ total $\operatorname{PDRB}$ di kecamatan $\mathrm{j}$; $\mathrm{Pi}=$ nilai PDRB sektor i pada tingkat DAS; $\mathrm{Pt}=$ total PDRB pada tingkat DAS

Nilai LQ dapat diinterpretasikan dengan menggunakan kriteria yang diringkas dalam Tabel 2 (Jamaliah \& Kurniawan, 2010; Muljaningsih, 2008; Sari, 2010).

Tabel 2. Penafsiran Nilai Location Quotient

\begin{tabular}{llll}
\hline \multirow{2}{*}{ Nilai LQ } & \multicolumn{1}{c}{\begin{tabular}{c} 
Sektor \\
\cline { 2 - 4 }
\end{tabular}} & \multicolumn{1}{c}{ Penafsiran } \\
\hline LQ $>1$ & $\begin{array}{l}\text { Sektor basis, unggulan dan } \\
\text { potensial }\end{array}$ & Tingkat Spesialisasi & \multicolumn{1}{c}{ Pelayanan Pasar } \\
LQ $<1$ & $\begin{array}{l}\text { Sektor nonbasis, non } \\
\text { unggulan dan tidak potensial }\end{array}$ & Sektor tidak terspesialisasi & $\begin{array}{l}\text { Ekspor, melayani pasar dalam } \\
\text { dan luar wilayah } \\
\text { Nonekspor. Belum mampu } \\
\text { melayani pasar luar wilayah }\end{array}$ \\
LQ $=1$ & $\begin{array}{l}\text { Sektor seimbang dengan } \\
\text { wilayah acuan }\end{array}$ & $\begin{array}{l}\text { Spesialisasi sama dengan } \\
\text { wilayah acuan }\end{array}$ & $\begin{array}{l}\text { Nonekspor, hanya mampu } \\
\text { melayani pasar di dalam } \\
\text { wilayah }\end{array}$ \\
\hline
\end{tabular}

Sektor unggulan di suatu wilayah dapat ditentukan apabila nilai LQ sektor lebih besar daripada 1. Nilai LQ yang lebih tinggi menunjukkan adanya keunggulan komparatif yang lebih tinggi pula dibandingkan dengan nilai LQ yang lebih rendah, begitu pula sebaliknya.

\section{Analisis Kontribusi Sektoral}

Analisis kontribusi sektoral dapat menunjukkan peran atau sumbangan suatu sektor tertentu terhadap perkembangan ekonomi daerah. Analisis ini merupakan perbandingan antara sumbangan ekonomi sektoral terhadap besarnya PDRB suatu daerah yang dinyatakan dalam persentase. Nilai kontribusi sektoral dapat diinterpretasikan yaitu 


\section{Identifikasi Sektor Ekonomi Unggulan di Daerah Tangkapan Air Danau Rawa Pening}

semakin besar nilai kontribusi sektoral yang diperoleh menunjukkan semakin besarnya peran suatu sektor dalam suatu perekonomian.

Hasil dan Pembahasan

\section{Deskripsi Kondisi Ekonomi Sub DAS Danau Rawa Pening}

Daerah Tangkapan Air Danau Rawa Pening merupakan salah satu bagian dari DAS Tuntang yang sebagian besar wilayahnya berada di Kabupaten Semarang dan sisanya berada di Kabupaten Salatiga. Sebagai gambaran kondisi ekonomi Daerah Tangkapan Air Danau Rawa Pening ditampilkan pada Tabel 3.

Tabel 3. Kondisi Ekonomi Kecamatan di Sub DAS Danau Rawa Pening

\begin{tabular}{|c|c|c|c|c|c|c|c|}
\hline \multirow[b]{2}{*}{ Kecamatan } & \multicolumn{2}{|c|}{ PDRB } & \multicolumn{2}{|c|}{ Jumlah Penduduk } & \multirow{2}{*}{$\begin{array}{l}\text { PDRB per } \\
\text { kapita } \\
\text { (ribu } \\
\text { rupiah) }\end{array}$} & \multirow[b]{2}{*}{$\begin{array}{l}\text { Pertumbuhan } \\
\text { Ekonomi (\%) }\end{array}$} & \multirow[b]{2}{*}{$\begin{array}{l}\text { Tipologi } \\
\text { Klassen* }\end{array}$} \\
\hline & $\begin{array}{c}\text { (juta } \\
\text { rupiah) }\end{array}$ & $(\%)$ & (jiwa) & $(\%)$ & & & \\
\hline Bawen & 1.438 .176 & 65,71 & 54.919 & 16,59 & $26.187,22$ & 5,02 & 3 \\
\hline Tuntang & 134.555 & 6,15 & 61.037 & 18,44 & $2.204,48$ & 20,42 & 2 \\
\hline Getasan & 193.590 & 8,85 & 48.658 & 14,70 & $3.978,58$ & 3,65 & 4 \\
\hline Banyubiru & 100.596 & 4,60 & 40.607 & 12,27 & $2.477,30$ & 1,65 & 4 \\
\hline Jambu & 72.054 & 3,29 & 37.051 & 11,20 & $1.944,72$ & 7,09 & 2 \\
\hline Sumowono & 126.397 & 5,78 & 30.038 & 9,08 & $4.207,90$ & 9,30 & 2 \\
\hline Ambarawa & 123.284 & 5,63 & 58.641 & 17,72 & $2.102,35$ & 14,08 & 2 \\
\hline $\begin{array}{l}\text { DAS Danau } \\
\text { Rawaapening }\end{array}$ & 2.188 .651 & & 330.951 & & $6.613,22$ & 6,35 & \\
\hline
\end{tabular}

Keterangan: untuk PDRB dihitung berdasarkan harga konstan dengan tahun dasar 2000. Nilai total/ratarata pada PDRB konstan dan jumlah penduduk merupakan nilai penjumlahan seluruh daerah dalam DAS Danau Rawa Pening, sedangkan untuk pertumbuhan ekonomi dan PDRB per kapita merupakan nilai ratarata dari seluruh daerah dalam DAS Danau Rawa Pening.

*1 = kecamatan yang cepat maju dan cepat tumbuh; $2=$ kecamatan yang maju tapi tertekan; $3=$ kecamatan yang berkembang cepat; dan $4=$ kecamatan yang tertinggal

Produk domestik regional bruto (PDRB) daerah tangkapan air Danau Rawa Pening mencapai 2.188 milyar rupiah. Pembentukan PDRB sebagian besar berada di Kecamatan Bawen sekitar 1.438 milyar rupiah (65,71\%) PDRB berasal dari kecamatan ini. Kondisi ini terjadi karena banyaknya aktivitas ekonomi bernilai tambah tinggi berada pada Kecamatan Bawen. Dilihat dari persebaran penduduknya, ada fenomena yang berbeda dibandingkan dengan kondisi PDRB dengan sebaran penduduk relatif merata di DTA Danau Rawa Pening. Namun demikian, sekitar 67\% penduduk DTA Danau Rawa Pening terkonsentrasi di Kecamatan Bawen, Tuntang, Getasan dan Ambarawa (lihat Tabel 3). Kecamatan Bawen, Tuntang, Getasan dan Ambarawa merupakan pusat ekonomi dan budaya sejak lama.

Dalam kacamata makro ekonomi, kesejahteraan masyarakat di Kecamatan Bawen merupakan yang terbaik dibandingkan dengan kecamatan lain di DTA Danau Rawa Pening, PDRB per kapita Kecamatan Bawen sebesar 26.187 juta rupiah lebih besar dibandingkan dengan rata-rata PDRB per kapita DTA Danau Rawa Pening yang berkisar 6,6 juta rupiah. Kondisi ini menunjukkan pula bahwa Kecamatan Bawen merupakan pusat ekonomi di DTA Danau Rawa Pening.

\section{Pola dan Struktur Pertumbuhan Ekonomi}

Berdasarkan analisis tipologi Klassen maka Kecamatan Bawen termasuk dalam tipologi tiga yaitu kecamatan maju tapi tertekan. Pendapatan per kapita di Kecamatan 
Bawen lebih tinggi dibandingkan dengan kecamatan lainnya tetapi pertumbuhan ekonominya lebih rendah dibandingkan dengan pertumbuhan ekonomi rata-rata DTA Danau Rawa Pening. Temuan ini berbeda dengan hasil penelitian Indriyani (2018) yang menyimpulkan Kecamatan Bawen, Bergas, Ungaran Barat dan Pabelan merupakan kecamatan yang berkembang pesat, meskipun data yang dipergunakan pada tahun yang sama. Perbedaan tersebut dikarenakan wilayah kajian yang berbeda (antara batas administrasi dan batas alamiah DTA) sehingga hasilnya berbeda, kecuali untuk Kecamatan Bawen.

Saat ini, kecamatan-kecamatan yang tergolong berkembang cepat (Tipologi 2) antara lain Kecamatan Tuntang, Jambu, Sumowono dan Ambarawa. Kecamatan-kecamatan ini sedang mengalami pertumbuhan ekonomi yang cepat dibandingkan dengan pertumbuhan ekonomi secara rata-rata di DTA Danau Rawa Pening. Hasil penelitian ini agak berbeda dengan Indriyani (2018) yang menyimpulkan Kecamatan Ambarawa, Sumowono dan Jambu tergolong kecamatan yang perkembangannya fluktuatif. Kecamatan yang berkembang pesat ini mempunyai potensi besar untuk berkembang tetapi belum dikelola dengan baik sehingga meskipun perkembangan ekonominya cepat tetapi pendapatan per kapita masih lebih rendah dibandingkan dengan rata-rata pendapatan per kapita daerah lain. Kecamatan Tuntang merupakan kecamatan dengan pertumbuhan ekonomi tercepat di DTA Danau Rawa Pening dengan laju pertumbuhan ekonomi mencapai 20,42\%, diikuti Kecamatan Ambarawa sebesar 14\%. Hasil penelitian ini mendukung penelitian Baskoro \& Hendarto (2018) yang menunjukkan bahwa Kecamatan Ambarawa berpotensi besar dalam pengembangan pariwisata terutama Bukit Cinta. Meskipun pengembangan objek wisata terkendala dengan pendangkalan, sedimentasi, eutrofikasi, eceng gondok dan kelembagaan.

Adapun kecamatan yang tergolong tertinggal (Tipologi 4) di DTA Danau Rawa Pening adalah Kecamatan Getasan dan Banyubiru. Kedua kecamatan ini memiliki pertumbuhan ekonomi yang lebih lambat dibandingkan laju ekonomi kecamatan lainnya dan kondisi pendapatan per kapita yang lebih rendah pula dibandingkan dengan rata-rata pendapatan per kapita di DTA Danau Rawa Pening. Penelitian ini seakan menjustifikasi penelitian Yusroni \& Chadhiq (2008) dan juga hasil kajian Indriyani (2018) yang menggolongkan Kecamatan Getasan dan Banyubiru termasuk kecamatan tertinggal, artinya kedua kecamatan tersebut tidak mampu berkembang ekonominya setelah lebih dari satu dekade.

\section{Penentuan SektorUnggulan dan Kontribusinya}

Dalam upaya mempercepat pembangunan ekonomi diperlukan suatu fokus pengembangan sektor ekonomi yang mampu meningkatkan pertumbuhan ekonomi dan menarik sektor lain untuk tumbuh. Sektor yang dipilih tersebut harus memiliki pertumbuhan yang positif. Sektor-sektor yang mengalami pertumbuhan positif apabila diperoleh nilai LQ lebih besar dari satu dan sektor-sektor yang mengalami pertumbuhan negatif apabila diperoleh nilai LQ lebih kecil dari satu. Hasil perhitungan LQ setiap kecamatan dalam DTA Danau Rawa Pening ditampilkan pada Tabel 4.

Hasil analisis menunjukkan bahwa sektor pertanian peternakan kehutanan perikanan, sektor listrik gas dan air bersih, sektor pengangkutan dan komunikasi, dan sektor jasa dapat dikembangkan di hampir semua kecamatan di DTA Danau Rawa Pening kecuali di Kecamatan Bawen. Sektor-sektor tersebut dapat dikembangkan karena merupakan sektor basis sehingga memiliki keunggulan komparatif. Namun, di Kecamatan Bawen pengembangan sektor-sektor tersebut tidak lagi memiliki keunggulan komparatif. Penelitian Pitricia, Hardati, \& Sanjoto (2016) menunjukkan bahwa Kecamatan Bawen merupakan daerah dengan alih fungsi lahan pertanian ke nonpertanian tertinggi, sehingga luas lahan pertanian semakin sempit. 


\section{Identifikasi Sektor Ekonomi Unggulan di Daerah Tangkapan Air Danau Rawa Pening}

Di sektor pertanian, peternakan, kehutanan dan perikanan terlihat bahwa sub sektor tanaman pangan dapat dikembangkan di DTA Danau Rawa Pening kecuali di Kecamatan Bawen dan Ambarawa, sedangkan perkebunan dapat diusahakan di Tuntang, Banyubiru, Jambu dan Sumowono. Hasil penelitian ini menunjukkan pertanian tidak memiliki keunggulan komparatif dikembangkan di Kecamatan Ambarawa dan dapat mendukung hasil penelitian Hidayati \& Soeprobowati (2017) yang menunjukkan bahwa penggunaan pupuk anorganik tertinggi berada di Kecamatan Ambarawa dan disarankan untuk mengembangkan pertanian ramah lingkungan. Untuk Perkebunan yang memiliki keunggulan komparatif terbesar berada di Kecamatan Jambu. Sedangkan untuk pengembangan peternakan dapat diarahkan di Kecamatan Getasan, Jambu, Sumowono, Tuntang dan Ambarawa. Sektor kehutanan masih memiliki keunggulan komparatif di Kecamatan Sumowono, Banyubiru, Jambu dan Getasan, tetapi tidak baik dikembangkan di Kecamatan Bawen, Tuntang dan Ambarawa.

Tabel 4. Sektor Ekonomi Unggulan Per Kecamatan di DAS Danau Rawa Pening Berdasarkan LQ

\begin{tabular}{|c|c|c|c|c|c|c|c|c|}
\hline \multirow{2}{*}{ No } & \multirow{2}{*}{ Sektor ekonomi } & \multicolumn{7}{|c|}{ Kecamatan di DAS Danau Rawa Pening } \\
\hline & & Bawen & Tuntang & Getasan & Banyubiru & Jambu & Sumowono & Ambarawa \\
\hline \multirow[t]{6}{*}{1} & $\begin{array}{l}\text { Pertanian, } \\
\text { peternakan, } \\
\text { kehutanan, } \\
\text { perikanan }\end{array}$ & 0.11 & 1.32 & 4.26 & 1.52 & 2.21 & 3.01 & 1.04 \\
\hline & a. Tanaman Pangan & 0.15 & 4.17 & 3.87 & 1.96 & 1.42 & 3.72 & 0.98 \\
\hline & b. Perkebunan & 0.12 & 2.48 & 0.78 & 2.28 & 7.55 & 3.87 & 0.72 \\
\hline & c. Peternakan & 0.04 & 1.33 & 5.65 & 0.58 & 2.43 & 2.04 & 1.11 \\
\hline & d. Kehutanan & 0.24 & 0.94 & 1.03 & 3.96 & 2.14 & 5.37 & 0.95 \\
\hline & e. Perikanan & 0.31 & 4.77 & 0.01 & 4.99 & 0.64 & 0.21 & 2.21 \\
\hline 2 & $\begin{array}{l}\text { Pertambangan dan } \\
\text { penggalian }\end{array}$ & 1.14 & 1.68 & 1.14 & 1.16 & 0.60 & 0.03 & 0.14 \\
\hline 3 & Industri pengolahan & 1.58 & 0.22 & 0.05 & 0.18 & 0.14 & 0.06 & 0.14 \\
\hline 4 & $\begin{array}{l}\text { Listrik, Gas dan air } \\
\text { bersih }\end{array}$ & 0.25 & 2.61 & 1.64 & 2.38 & 3.61 & 1.82 & 1.75 \\
\hline 5 & Konstruksi & 0.13 & 3.58 & 1.06 & 4.69 & 0.18 & 2.17 & 2.21 \\
\hline 6 & $\begin{array}{l}\text { Perdagangan, hotel } \\
\text { dan restoran }\end{array}$ & 1.06 & 1.17 & 0.43 & 1.10 & 0.68 & 0.82 & 1.31 \\
\hline 7 & $\begin{array}{l}\text { Pengangkutan dan } \\
\text { komunikasi }\end{array}$ & 0.14 & 2.40 & 2.56 & 1.31 & 3.77 & 2.02 & 2.11 \\
\hline 8 & $\begin{array}{l}\text { Keuangan, real } \\
\text { estate dan jasa } \\
\text { perusahaan }\end{array}$ & 0.25 & 1.91 & 0.93 & 2.40 & 2.24 & 1.51 & 3.84 \\
\hline 9 & Jasa-jasa & 0.22 & 2.28 & 1.38 & 2.09 & 3.11 & 1.98 & 2.78 \\
\hline
\end{tabular}

Industri ekstaktif seperti pertambangan dan pengalian di DTA Danau Rawa Pening dapat diusahakan di Tuntang, Banyubiru, Bawen dan Getasan. Industri pengolahan akan unggul dikembangkan di Kecamatan Bawen, sedangkan di daerah lain kurang baik dilakukan. Sektor konstruksi memiliki keungulan di hampir semua daerah di Danau Rawa Pening kecuali di Bawen dan Jambu. Untuk pengembangan perdagangan, hotel dan restoran sebaiknya dilakukan di Kecamatan Bawen, Tuntang, Banyubiru dan Ambarawa, begitu pula dengan sektor keuangan, real estate dan jasa perusahaan tidak baik dikembangkan di Bawen dan Getasan tetapi baik dikembangkan di kecamatan lainnya.

Kecamatan Bawen yang memiliki PDRB terbesar di DTA Danau Rawa Pening ternyata memiliki keunggulan komparatif pada sektor pertambangan dan pengalian, 
Industri pengolahan, dan sektor perdagangan hotel dan restoran. Wilayah yang dekat dengan Kota Semarang mengoptimalkan keungulan Kota Semarang yang unggul pada perdagangan, hotel dan restoran (Miroah, 2015). Pada Kecamatan Bawen sektor ekonomi pertanian, peternakan, perikanan dan kehutanan tidak berkembang karena kurang memiliki keunggulan komparatif. Hal ini dapat menjelaskan kenapa proyek pemberdayaan ecofarming di Bawen berdasarkan penelitian Farikhah, Fatimah, \& Luthfi (2018) dikatakan gagal, karena Bawen tidak unggul secara komparatif untuk pertanian dan kurangnya dukungan masyarakat sehingga program tersebut tidak berkelanjutan, sedangkan kecamatan yang berkembang pesat seperti Tuntang, Jambu, Sumowono dan Ambarawa mengandalkan pertumbuhannya pada hampir semua sektor ekonomi kecuali sektor industri pengolahan.

Sektor ekonomi unggulan setiap kecamatan DTA Danau Rawa Pening bervariasi baik jumlah maupun jenisnya tergantung pada sumber daya dan keunggulan komparatif sektor di setiap daerah. Ketersediaan sumber daya (alam, manusia, modal dan lainnya), infrastruktur, kebijakan pendukung dan lainnya akan memengaruhi perkembangan sektor unggulan tersebut. Pengembangan sektor ekonomi unggulan dapat lebih mengalokasikan sumber daya dengan tepat.

Setiap sektor ekonomi berkontribusi dalam perkembangan baik di DTA Danau Rawa Pening maupun di kecamatannya. Kontribusi sektoral tersebut menunjukkan perannya dalam perekonomian, semakin besar kontribusinya berarti semakin penting dan berpengaruh sektor tersebut (Tabel 5 dan 6). Tabel menunjukkan bahwa 60\% ekonomi DTA Danau Rawa Pening berada di Kecamatan Bawen dengan kontribusi terbesar pada sektor industri pengolahan, pertambangan dan pengalian, perdagangan hotel dan restoran. Ketiga sektor tersebut sangat dominan dalam perekonomian Kecamatan Bawen. Hal ini sesuai dengan hasil diskusi dengan Badan Perencanaan Pembangunan Daerah dan Pemerintah Provinsi Jawa Tengah yang menjadikan Kecamatan Bawen sebagai salah satu pusat pertumbuhan ekonomi di Jawa Tengah, meskipun belum dipahami potensi dan keunggulan wilayah ini. Pengamatan lapangan menunjukkan banyak industri di kecamatan ini dengan infrastruktur yang bagus serta dekat dengan Kota Semarang sehingga potensial dikembangkan sebagai pusat pertumbuhan ekonomi. Kontribusi Kecamatan Tuntang terutama pada perikanan dan sektor listrik gas dan air bersih. Kecamatan Tuntang merupakan lokasi PLTA Jelok dan PLTA Timo, salah satu pemasok energi listrik interkoneksi Jawa Bali dan merupakan PLTA pertama di Indonesia. Untuk pertanian peternakan kehutanan terutama sub sektor tanaman pangan dan peternakan peran terbesar dilakukan Kecamatan Getasan yang mencapai 41\%. Potensi Kecamatan Getasan terutama di pertanian, kehutanan, peternakan. Salah satunya di Kopeng yang merupakan sentra utama komoditas pertanian seperti sayuran dan tanaman hias. Selain itu Getasan berkontribusi hampir 25\% untuk pembentukan sektor pengangkutan dan komunikasi di DTA Danau Rawa Pening. Pengangkutan komoditas pertanian, kehutanan, dan peternakan ke daerah lainnya di Jawa membuat kontribusi sektor angkutan dan transportasi cukup besar di Kecamatan Getasan. Hampir sama dengan Banyubiru yang memiliki share 25\% dalam sektor konstruksi yang mulai berkembang. Banyubiru mulai berkembang hotel, infrastruktur dan pariwisata sehingga sektor konstruksi mulai menjadi tumpuan ekonominya. Untuk sektor kehutanan, sepertiga kontribusinya diberikan oleh Kecamatan Sumowono. Adapun Kecamatan Ambarawa berkontribusi besar dalam sektor keuangan real estate dan jasa perusahaan serta sektor jasa-jasa. Kecamatan Ambarawa unggul di sektor jasa dan keungan serta perumahan karena Ambarawa merupakan bekas ibukota Kabupaten Semarang sehingga infrastruktur lebih baik dan menjadi pusat ekonomi di masa lalu. Selain itu Kecamatan Ambarawa merupakan pusat pemukiman penduduk sebagai dampak dari perannya di masa lalu. 


\section{Identifikasi Sektor Ekonomi Unggulan di Daerah Tangkapan Air Danau Rawa Pening}

Adapun kontribusi sektor ekonomi terhadap ekonomi kecamatan di DTA Danau Rawa Pening ditampilkan Tabel 5. Tabel 5 ini menunjukkan peran dominan suatu sektor dalam perekonomian di Kecamatan tersebut, Semakin besar persentasenya menunjukkan bahwa sektor tersebut makin penting bagi perekonomian kecamatan.

Tabel 5. Kontribusi Sektoral terhadap Ekonomi di DAS Danau Rawa Pening

\begin{tabular}{|c|c|c|c|c|c|c|c|c|}
\hline \multirow{2}{*}{ No } & \multirow{2}{*}{ Sektor } & \multicolumn{7}{|c|}{ Kontribusi Sektoral Kecamatan di DAS Danau Rawa Pening (dalam persen) } \\
\hline & & Bawen & Tuntang & Getasan & Banyubiru & Jambu & Sumowono & Ambarawa \\
\hline \multirow[t]{6}{*}{1} & $\begin{array}{l}\text { Pertanian, peternakan, } \\
\text { kehutanan, perikanan }\end{array}$ & 6.73 & 8.60 & 41.37 & 8.26 & 7.99 & 17.94 & 9.11 \\
\hline & a. Tanaman Pangan & 7.64 & 22.57 & 31.21 & 8.80 & 4.25 & 18.40 & 7.13 \\
\hline & b. Perkebunan & 7.18 & 16.16 & 7.57 & 12.36 & 27.33 & 23.07 & 6.33 \\
\hline & c. Peternakan & 2.62 & 8.65 & 54.88 & 3.17 & 8.79 & 12.17 & 9.72 \\
\hline & d. Kehutanan & 14.30 & 6.16 & 10.00 & 21.45 & 7.75 & 32.00 & 8.34 \\
\hline & e. Perikanan & 18.76 & 31.15 & 0.08 & 27.08 & 2.33 & 1.27 & 19.33 \\
\hline 2 & $\begin{array}{l}\text { Pertambangan dan } \\
\text { penggalian }\end{array}$ & 68.11 & 10.97 & 11.10 & 6.28 & 2.17 & 0.15 & 1.21 \\
\hline 3 & Industri pengolahan & 94.96 & 1.44 & 0.50 & 0.99 & 0.51 & 0.35 & 1.25 \\
\hline 4 & $\begin{array}{l}\text { Listrik, Gas dan air } \\
\text { bersih }\end{array}$ & 14.91 & 17.02 & 15.90 & 12.90 & 13.06 & 10.87 & 15.33 \\
\hline 5 & Konstruksi & 8.00 & 23.33 & 10.32 & 25.42 & 0.63 & 12.92 & 19.39 \\
\hline 6 & $\begin{array}{l}\text { Perdagangan, hotel } \\
\text { dan restoran }\end{array}$ & 63.38 & 7.62 & 4.19 & 5.95 & 2.45 & 4.90 & 11.51 \\
\hline 7 & $\begin{array}{l}\text { Pengangkutan dan } \\
\text { komunikasi }\end{array}$ & 8.23 & 15.63 & 24.88 & 7.10 & 13.65 & 12.03 & 18.47 \\
\hline 8 & $\begin{array}{l}\text { Keuangan, real estate } \\
\text { dan jasa perusahaan }\end{array}$ & 14.75 & 12.44 & 9.05 & 13.01 & 8.09 & 9.00 & 33.66 \\
\hline \multirow[t]{2}{*}{9} & Jasa-jasa & 12.97 & 14.90 & 13.39 & 11.33 & 11.25 & 11.81 & 24.36 \\
\hline & $\begin{array}{l}\text { DAS Danau Rawa } \\
\text { Pening }\end{array}$ & 59.99 & 6.52 & 9.72 & 5.42 & 3.62 & 5.96 & 8.76 \\
\hline
\end{tabular}

Kecamatan Bawen mengandalkan 70\% perekonomiannya pada sektor industri pengolahan. Berdasakan survei lapangan yang dilakukan menunjukkan banyak industri pengolahan di Kecamatan Bawen seperti PT Apac Inti Corpora, PT Coca Cola Amatil Indonesia, PT Liebra Permana dan sebagainya. Industri pengolahan berdampak pada lingkungan apabila pengolahan limbahnya tidak memadai akan tetapi berdasarkan hasil penilaian kerusakan sumber daya alam dan lingkungan oleh Partomo et al. (2011) menyimpulkan Kecamatan Bawen dan Banyubiru, tingkat kerentanan kerusakan lingkungannya tergolong sedang. Hasil temuan ini berbeda dengan penelitian Subanti (2015) yang menyimpulkan sektor pariwisata memberi kontribusi terbesar pada perekonomian di Rawa Pening. Kesimpulan tersebut kemungkinan didasarkan pada data untuk seluruh Kabupaten Semarang bukan khusus pada daerah sekitar Rawa Pening sehingga objek wisata yang tidak masuk DTA Rawa Pening masuk dalam analisisnya.

Perekonomian Kecamatan Tuntang didominasi oleh sektor perdagangan hotel dan restoran. Perdagangan, hotel dan restoran merupakan salah satu prospek yang menjanjikan kesejahteraan serta tidak membutuhkan pendidikan tinggi tetapi bernilai tambah tinggi. Banyak hotel yang berada di Kecamatan Tuntang yang mendukung perkembangan pariwisata di Danau Rawa Pening. Untuk Kecamatan Getasan didominasi oleh sektor pertanian peternakan kehutanan (62\%) terutama tanaman pangan dan peternakan, sedangkan kontribusi sektor lain di bawah $10 \%$. Sektor pertanian, perikanan, peternakan, 
perkebunan dan kehutanan merupakan sektor penyerap tenaga kerja yang besar meskipun sumbangannya pada pendapatan wilayah relatif kecil.

Tabel 6. Kontribusi Sektor Ekonomi terhadap Ekonomi Kecamatan di DAS Danau Rawa Pening

\begin{tabular}{|c|c|c|c|c|c|c|c|c|}
\hline \multirow{2}{*}{ No } & \multirow{2}{*}{ Sektor Ekonomi } & \multicolumn{7}{|c|}{ Kontribusi Sektoral Kecamatan di DAS Danau Rawa Pening (dalam persen) } \\
\hline & & Bawen & Tuntang & Getasan & Banyubiru & Jambu & Sumowono & Ambarawa \\
\hline \multirow[t]{6}{*}{1} & $\begin{array}{l}\text { Pertanian, peternakan, } \\
\text { kehutanan, perikanan }\end{array}$ & 1.65 & 19.42 & 62.68 & 22.43 & 32.52 & 44.36 & 15.31 \\
\hline & a. Tanaman Pangan & 1.15 & 31.14 & 28.89 & 14.60 & 10.57 & 27.80 & 7.32 \\
\hline & b. Perkebunan & 0.12 & 2.39 & 0.75 & 2.20 & 7.29 & 3.74 & 0.70 \\
\hline & c. Peternakan & 0.25 & 7.70 & 32.76 & 3.39 & 14.10 & 11.85 & 6.43 \\
\hline & d. Kehutanan & 0.04 & 0.16 & 0.17 & 0.67 & 0.36 & 0.91 & 0.16 \\
\hline & e. Perikanan & 0.10 & 1.50 & 0.00 & 1.57 & 0.20 & 0.07 & 0.69 \\
\hline 2 & $\begin{array}{l}\text { Pertambangan dan } \\
\text { penggalian }\end{array}$ & 0.20 & 0.30 & 0.20 & 0.20 & 0.11 & 0.00 & 0.02 \\
\hline 3 & Industri pengolahan & 70.31 & 9.83 & 2.29 & 8.12 & 6.23 & 2.60 & 6.34 \\
\hline 4 & $\begin{array}{l}\text { Listrik, Gas dan air } \\
\text { bersih }\end{array}$ & 0.21 & 2.21 & 1.39 & 2.02 & 3.06 & 1.55 & 1.48 \\
\hline 5 & Konstruksi & 0.39 & 10.58 & 3.14 & 13.87 & 0.52 & 6.42 & 6.55 \\
\hline 6 & $\begin{array}{l}\text { Perdagangan, hotel dan } \\
\text { restoran }\end{array}$ & 24.33 & 26.91 & 9.93 & 25.29 & 15.60 & 18.94 & 30.26 \\
\hline 7 & $\begin{array}{l}\text { Pengangkutan dan } \\
\text { komunikasi }\end{array}$ & 0.30 & 5.30 & 5.66 & 2.89 & 8.34 & 4.46 & 4.66 \\
\hline 8 & $\begin{array}{l}\text { Keuangan, real estate } \\
\text { dan jasa perusahaan }\end{array}$ & 0.71 & 5.51 & 2.69 & 6.93 & 6.46 & 4.36 & 11.09 \\
\hline 9 & Jasa-jasa & 1.89 & 19.95 & 12.02 & 18.25 & 27.17 & 17.31 & 24.28 \\
\hline
\end{tabular}

Keberadaan Kawasan Kopeng sebagai pusat hortikultura dan tanaman hias mampu mendorong perekonomian kawasan ini yang berbasis sektor primer dan didukung dengan banyaknya penduduk sebagai petani. Kecamatan Banyubiru serupa dengan Kecamatan Tuntang dan Ambarawa yang perekonomiannya lebih dari 25\% ditopang dari perkembangan perdagangan, hotel dan restoran. Namun untuk Kecamatan Tuntang dan Ambarawa perlu diperhatikan persoalan kerusakan sumber daya alam dan lingkungannya, karena dari hasil penelitian Partomo et al. (2011), kedua kecamatan tersebut termasuk kecamatan dengan kerentanan tinggi. Kondisi ini karena usaha yang berkembang pada daerah tersebut sebagian besar merupakan usaha kecil dan menengah yang kurang terlalu memerhatikan lingkungan dan kelestarian sumber daya. Pengawasan dan sosialisasi serta peningkatan kapasitas diperlukan sehingga mampu menurunkan kerentanan lingkungan pada kawasan ini. Hal yang sama terlihat pada Kecamatan Jambu dan Sumowono yang didominasi oleh sektor pertanian, peternakan, kehutanan, perkebunan, dan perikanan. Meskipun sektor primer ini bukan pendorong pertumbuhan ekonomi tetapi sektor ini berperan penting dalam perekonomian terutama untuk ketersediaan pangan, bahan baku industri, komoditi ekspor dan ketahanan pangan. Oleh karena itu, kebijakan fiskal, moneter, perdagangan dan politik tidak mengabaikan potensi sektor pertanian, perikanan, perkebunan dan kehutanan. Untuk itu, pada daerah dengan kontribusi utama dari sektor primer perlu diperhatikan kondisi irigasi dan infrastruktur pertanian yang sebagian besar penduduknya sebagai petani.

Kecamatan yang memiliki keunggulan di sektor industri perlu didorong agar meningkatkan produktifitas dan berkontribusi bagi perkembangan daerah lain, terutama memanfaatkan sumber daya alam, tenaga kerja, dan alokasi kegiatannya. Berdasarkan 


\section{Identifikasi Sektor Ekonomi Unggulan di Daerah Tangkapan Air Danau Rawa Pening}

uraian tersebut, terdapat perbedaan karakteristik di setiap kecamatan dalam DTA Danau Rawa Pening sehingga setiap kecamatan tersebut memiliki kemampuan yang berbeda dalam pengembangan ekonominya. Kecamatan yang dapat mengali potensi wilayahnya dan didukung dengan infrastruktur yang menunjang akan memiliki pertumbuhan ekonomi dan pendapatan per kapita ekonomi yang tinggi.

Sektor-sektor ekonomi unggulan pada umumnya memberikan kontribusi yang relatif signifikan terhadap perkembangan ekonomi kecamatan dan DTA Danau Rawa Pening. Semakin besar kontribusinya terhadap PDRB menunjukkan peran dan strategisnya sektor tersebut dalam pembangunan daerah. Berdasarkan penelitian ini, untuk pengembangan ekonowi kawasan daerah tangkapan air Rawa Pening sebaiknya diprioritaskan pada sektor ekonomi unggulan dengan mempertimbangkan proporsi sektor lain sesuai dengan potensi daerahnya. Selain itu, pengembangan usaha kecil dan menengah di seluruh wilayah sekitar DTA Danau Rawa Pening agar dapat meningkatkan perekonomian masyarakat dan wilayah dengan cara peningkatan kualitas sumber daya manusia, kemudahan berusaha dan perijinan yang mendukung investasi yang kondusif.

\section{Kesimpulan}

Penelitian ini telah mengisi kekosongan kajian ekonomi wilayah di daerah tangkapan air Danau Rawa Pening yang mengalami persoalan kompleks serta menjawab sektor ekonomi unggulan untuk perencanaan pengembangan kawasan daerah tangkapan air Danau Rawa Pening yang lebih baik. Kecamatan Bawen merupakan daerah maju tetapi tertekan dengan kontribusi 65\% dari total perekonomian di DTA Danau Rawa Pening, terutama dari sektor industri pengolahan. Kecamatan yang maju pesat antara lain Kecamatan Tuntang, Jambu, Sumowono, dan Ambarawa yang pertumbuhan ekonominya di atas rata-rata. Kecamatan yang tumbuh pesat ini mengandalkan perkembangannya hampir pada semua sektor ekonomi kecuali sektor industri pengolahan. Kecamatan yang tertinggal yaitu Getasan dan Banyubiru masih mengandalkan keunggulan ekonominya pada sektor primer seperti pertanian, peternakan, kehutanan, perkebunan, dan perikanan, kecuali Banyubiru yang berperan penting di sektor perdagangan, hotel, dan restoran. Sektor unggulan setiap daerah kecamatan di DTA Danau Rawa Pening berbeda tergantung kondisi sumber daya dan keunggulan komparatif yang dimilikinya. Sektor ekonomi unggulan berkontribusi relatif signifikan pada perkembangan perekonomian di DTA Danau Rawa Pening.

Penelitian ini menunjukkan bahwa teori basis dengan location quotient dapat dipergunakan pada daerah dengan batas alamiah seperti daerah tangkapan air Danau Rawa Pening. Perencanaan pembangunan sebaiknya memerhatikan keunggulan ekonomi setiap wilayah sehingga pembangunan dapat efisien dalam alokasi sumber daya dan anggaran yang makin terbatas. Peningkatan ekonomi daerah di DTA Danau Rawa Pening dapat diakselerasi dengan pengembangan sektor ekonomi unggulan yang ada pada daerah kecamatan dengan memerhatikan ketersediaan sumber daya, infrastruktur dan kebijakan yang mendukungnya. Selain itu pengembangan sektor ekonomi unggulan tersebut perlu memerhatikan pencemaran dan pengolahan limbahnya sehingga tidak mencemari dan memperburuk kondisi Danau Rawa Pening.

\section{Ucapan Terima Kasih}

Penulis berterima kasih kepada Balai Penelitian dan Pengembangan Teknologi Pengelolaan Daerah Aliran Sungai (BPPTPDAS), Badan Penelitian, Pengembangan dan Inovasi, Kementerian Lingkungan Hidup dan Kehutanan (KLHK) atas dukungan biaya pada 
kegiatan penelitian "Tata Kelola Pemulihan Fungsi Sempadan Danau Rawa Pening untuk Mengurangi Eutrofikasi dan Sedimentasi" Terima kasih juga disampaikan kepada seluruh tim peneliti dan teknisi yang telah membantu dalam pengumpulan data penelitian ini.

\section{Daftar Pustaka}

Aida, S. N., \& Utomo, A. D. (2017). Kajian kualitas perairan untuk perikanan di rawa pening Jawa Tengah. BAWAL Widya Riset Perikanan Tangkap, 8(3), 173-182.

Ardi, A. D., \& Rahayu, S. (2013). Kajian kesesuaian perubahan penggunaan lahan terhadap arahan pemanfaatan fungsi kawasan Sub DAS Rawapening. Teknik PWK (Perencanaan Wilayah Kota), 2(4), 958-967.

Bangun, R. H. (2018). Analisis prioritas pembangunan wilayah berdasarkan sektor produk domestik regional bruto Kabupaten Tapanuli Tengah-Sumatera Utara. Jurnal Litbang Sukowati: Media Penelitian dan Pengembangan, 2(1), 19-35. doi:10.32630/sukowati.v2i1.38.

Bappeda Provinsi Jawa Tengah. (2005). Penyusunan action plan pengembangan kawasan Rawapening. Laporan Akhir. CV. Galihloka Semarang.

Baskoro, A. W. N., \& Hendarto, R. M. (2018). Strategi pengembangan objek wisata bukit cinta rawa pening. Fakultas Ekonomika dan Bisnis.

Berawi, M. A., Zagloel, T. Y., Miraj, P., \& Mulyanto, H. (2017). Producing alternative concept for the transsumatera toll road project development using location quotient method. Procedia Engineering, 171, 265273. doi:10.1016/j.proeng.2017.01.334.

Billings, S. B., \& Johnson, E. B. (2012). The location quotient as an estimator of industrial concentration. Regional Science and Urban Economics, 42(4), 642-647. doi:10.1016/j.regsciurbeco.2012.03.003.

Cahyono, S. A., \& Wijaya, W. W. (2014). Identifikasi sektor ekonomi unggulan dan ketimpangan pendapatan antar kabupaten di sub DAS Bengawan Solo Hulu. Jurnal Penelitian Sosial dan Ekonomi Kehutanan, 11(1), 32-43. doi:10.20886/jsek.2014.11.1.32-43.

Cristianawati, C. (2017). Tradisi masyarakat nelayan Rawa Pening Kelurahan Bejalen Kecamatan Ambarawa Kabupaten Semarang. Sabda: Jurnal Kajian Kebudayaan, 12(2), 155-160. doi:10.14710/sabda.12.2.155160.

Darwin, R. (2017). Analisis Potensi sektor basis di Kota Pekanbaru. Jurnal Ekonomi dan Bisnis Dharma Andalas, $18(2), 336$.

Direktorat Jenderal Sumber Daya Air Balai Besar Wilayah Sungai Pemali Juana. (2016). Studi masterplan danau rawa pening. Semarang.

Erna, F., Harisudin, M., \& Rahayu, W. (2017). Analisis peran subsektor pertanian terhadap pembangunan Kabupaten Karanganyar: sebuah pendekatan comparative performance index. SEPA: Jurnal Sosial Ekonomi Pertanian dan Agribisnis, 14(1), 28-38.

Faijah, N., \& Wahbi, A. A. (2017). Metode spasial dalam memetakan sektor peternakan unggulan di Indonesia. JABE (Journal of Applied Business and Economic), 1(2), 135-145. doi:10.30998/jabe.v1i2.1394.

Farida, I. (2017). Identifikasi pusat pertumbuhan dan interaksi spasial di Provinsi Lampung. Fakultas Ekonomi dan Bisnis.

Farikhah, S., Fatimah, N., \& Luthfi, A. (2018). Pemberdayaan masyarakat melalui program integrated ecofarming (studi kasus di desa Asinan Kecamatan Bawen kabupaten Semarang). SOCA: Jurnal Sosial Ekonomi Pertanian, 12(1), 1-14. doi:10.24843/SOCA.2018.v12.i01.p01.

Fikri, M. T., \& Fafurida, F. (2018). Sektor unggulan dan keterkaitan spasial ekonomi antar kabupaten/kota di Jawa Tengah. Economics Development Analysis Journal, 73), 243-250. doi:10.15294/edaj.v7i3.25256.

Gerhard, G., \& Susilowati, I. (2013). Valuasi ekonomi sumberdaya alam rawa pening dan strategi pelestariannya di Kabupaten Semarang. Fakultas Ekonomika dan Bisnis Universitas Diponegoro.

Girsang, A., Rut P, R., Dyah, I., \& Nurkertamanda, D. (2019). Usulan strategi pengembangan wisata yang berkelanjutan di Bukit Cinta Rawa Pening dengan menggunakan SWOT analisis dan pendekatan analytical network process. Industrial Engineering Online Journal, 8(1).

Guimarães, P., Figueiredo, O., \& Woodward, D. (2009). Dartboard tests for the location quotient. Regional Science and Urban Economics, 39(3), 360-364. doi:10.1016/j.regsciurbeco.2008.12.003.

Hadi, M. F., Suciati, S., \& Asnawi, M. (2018). Analisis penentuan sektor unggulan dalam penyerapan tenaga 


\section{Identifikasi Sektor Ekonomi Unggulan di Daerah Tangkapan Air Danau Rawa Pening}

kerja di Kabupaten Indragiri Hulu, pendekatan tipologi Klassen. Jurnal Akuntansi dan Ekonomika, 8(2), 198-208.

Haryani, G. (2010). Bencana perairan darat di Indonesia: membangun kapasitas kesiapsiagaan bersama masyarakat. In Prosiding Seminar Nasional Limnologi V 2010; prospek ekosistem perairan darat Indonesia: mitigasi bencana dan peran masyarakat. Pusat Penelitian Limnologi LIPI.

Heriza, D., Sukmono, A., \& Bashit, N. (2018). Analisis perubahan kualitas perairan Danau Rawa Pening periode 2013, 2015 dan 2017 dengan menggunakan data citra Landsat 8 multitemporal. Jurnal Geodesi Undip, 71), 79-89.

Hidayati, N, Soeprobowati, T. R., \& Helmi, M. (2018). The evaluation of water hyacinth (Eichhornia crassiper) control program in Rawapening Lake, Central Java Indonesia. In IOP Conference Series: Earth and Environmental Science (Vol. 142, p. 12016). doi:10.1088/1755-1315/142/1/012016.

Hidayati, Neny, \& Soeprobowati, T. R. (2017). Pertanian ramah lingkungan di daerah tangkapan air Danau Rawa Pening. In Proceeding Biology Education Conference: Biology, Science, Enviromental, and Learning (Vol. 14, pp. 126-130).

Ibrahim, I. (2018). Analisis potensi sektor ekonomi dalam upaya peningkatan pertumbuhan ekonomi (studi empiris pada kabupaten dan kota di Provinsi Gorontalo tahun 2012-2016). Gorontalo Development Review, 1(1), 44-58.

Indriyani, F. (2018). Analisis ketimpangan antar wilayah kecamatan di Kabupaten Semarang tahun 2009-2013. Universitas Diponegoro.

Iyan, R. (2014). Analisis komoditas unggulan sektor pertanian di Wilayah Sumatera. Jurnal Sosial Ekonomi Pembangunan, 4(11), 215-234.

Jamaliah, H., \& Kurniawan, A. (2010). Analisis struktur ekonomi serta basis ekonomi di Propinsi Kalimantan Barat. Jurnal Ekonomi Bisnis dan Kewirausahaan (JEBIK), 1(2), 67-81.

Kementerian Lingkungan Hidup. (2010). Program danau prioritas nasional tahun 2010-2014. Jakarta.

Kementerian Lingkungan Hidup. (2011). Gerakan Penyelamatan Danau (Germadan) Rawa Pening. Jakarta.

Kesuma, N. L. A., \& Utama, I. M. S. (2015). Analisis sektor unggulan dan pergeseran pangsa ekonomi kabupaten Klungkung. Jurnal Ekonomi Kuantitatif Terapan, 8(1), 100-107.

Listyana, N. H. (2016). Analisis tanaman obat yang menjadi prioritas untuk dikembangkan di Jawa Tengah. SEPA: Jurnal Sosial Ekonomi Pertanian dan Agribisnis, 13(1), 90-97. doi:10.20961/sepa.v13i1.14246.

Miroah, C. (2015). Analisis penentuan sektor unggulan kota Semarang melalui pendekatan tipologi Klassen. Universitas Negeri Semarang.

Muljaningsih, S. (2008). Keberadaan pasar memberikan multiplier efect terhadap pengembangan ekonomi wilayah: studi kasus di lingkup wilayah Pasar Gempol Kab. Pasuruan Prop. Jawa Timur. Jurnal Agribisnis Kerakyatan, 1(2), 16-47.

Mustofa, L. J., \& Haryati, T. (2018). Analisis tipologi potensi pariwisata di Provinsi Jawa Tengah. Economics Development Analysis Journal, 72), 186-193. doi:10.15294/edaj.v7i2.23416.

Nadjib, M. (2016). Problematika prinsip manajemen kolaboratif dalam kerangka penyelamatan Danau Rawapening. Jurnal Masyarakat dan Budaya, 18(3), 487-502.

Nindhitya, R. O. (2013). Pemetaan sub sektor pertanian dalam rangka pengembangan perekonomian daerah Kabupaten Wonosobo. Economics Development Analysis Journal, 2(1). doi:10.15294/edaj.v2i1.1003.

Ningrum, P. A. (2017). Analisis potensi sektor basis dan non basis ekonomi pada perubahan struktur perekonomian di Kota Salatiga tahun 2010-2015. Universitas Muhammadiyah Surakarta.

Ningsih, Y. W., Kurniawan, T., Rahmawati, A. N., Permatasari, D. A., Ghunarso, D. A.-H., Pratama, R. A., ... Widiyatmoko, W. (2019). Persepsi masyarakat terhadap tanaman eceng gondok Rawa Pening di Desa Banyubiru Kabupaten Semarang. Jurnal Geografi, Edukasi Dan Lingkungan (JGEL), 3(2), 83-91. doi:10.29405/jgel.v3i2.3488.

Nugroho, N. P. (2017). Estimasi hasil air dari daerah tangkapan air Danau Rawa Pening dengan menggunakan Model Invest. Majalah Ilmiah Globë, 19(2), 157-166. doi:10.24895/MIG.2017.19-2.578.

Nuraini, R. A., \& Setiartiti, L. (2017). Strategi Pengembangan Kota Magelang sebagai Kawasan Andalan di Provinsi Jawa Tengah. Jurnal Ekonomi \& Studi Pembangunan, 18(2), 173-182.

Partomo, P., Mangkuprawira, S., Hubeis, A. V. S., \& Adrianto, L. (2011). Pengelolaan danau berbasis comanagement: kasus Rawa Pening. Jurnal Pengelolaan Sumberdaya Alam Dan Lingkungan (Journal of 
Natural Resources and Environmental Management), 1(2), 106-113.

Pinem, D. E. (2016). Menemukan strategi pengembangan kawasan industri melalui analisis sektor unggulan Kota Binjai. Jurnal Wilayah dan Lingkungan, 4(1), 45-64.

Piranti, A. S., Rahayu, D. R. U. S., \& Waluyo, G. (2018). Evaluasi status mutu air Danau Rawa Pening. Journal of Natural Resources and Environmental Management, 8(2), 151-160. doi:10.29244/jpsl.8.2.151-160.

Pitricia, N., Hardati, P., \& Sanjoto, T. B. (2016). Pengaruh alih guna lahan sawah ke non sawah terhadap perubahan mata pencaharian dan asset keluarga Kecamatan Bawen. Geo-Image, 5(2), 1-7. doi:10.15294/geoimage.v5i2.13558.

Purboseno, S. (2013). Evaluasi karakteristik daerah tangkapan air sebagai acuan kegiatan konservasi Sumber Daya Air. In Prosiding Seminar Nasional Pengelolaan Sumberdaya Alam dan Lingkungan (pp. 226-231).

Pusat Bendung Kementerian Pekerjaan Umum. (2018). Penanganan danau rawa pening Kabupaten Semarang. Semarang.

Pusat Limnologi LIPI. (2011). Sistem informasi danau Indonesia.

Raharjo, S. A. S., Falah, F., \& Cahyono, S. A. (2019). Germadan Rawa Pening: tindakan bersama dalam pengelolaan common pool resources. Jurnal Penelitian Pengelolaan Daerah Aliran Sungai, 3(1), 1-12. doi:10.20886/jppdas.2019.3.1.1-12.

Restiatun, R. (2009). Identifikasi sektor unggulan dan ketimpangan antar kabupaten/kota di Propinsi daerah Istimewa Yogyakarta. Jurnal Ekonomi \& Studi Pembangunan, 19(1), 30666.

Ridwan, B. (2013). Kesadaran dan tanggungjawab pelestarian lingkungan masyarakat muslim Rawa Pening Kabupaten Semarang. INFERENSI: Jurnal Penelitian Sosial Keagamaan, 72), 321-342.

Riyardi, A. (2013). Deindustrialisasi pada industry tekstil dan produksi tekstil di Pulau Jawa. JEJAK: Jurnal Ekonomi dan Kebijakan, 6(1), 106-119. doi:10.15294/jejak.v6i1.3752.

Rustiadi, E. (2018). Perencanaan dan pengembangan wilayah. Jakarta: Yayasan Pustaka Obor Indonesia.

Sari, R. M. (2010). Analisis komoditas unggulan pertanian di Pulau Buru, Provinsi Maluku. Jurnal Agroforestri, 5(3), 228-236.

Seftyono, C. (2014). Rawa Pening dalam perspektif politik lingkungan: sebuah kajian awal. Indonesian Journal of Conservation, 3(1), 7-15.

Setianto, P., \& Susilowati, I. (2014). Komoditas perkebunan unggulan yang berbasis pada pengembangan wilayah kecamatan di Kabupaten Banjarnegara Provinsi Jawa Tengah. Jurnal Wilayah Dan Lingkungan, 2(2), 143-156. doi:10.14710/jwl.2.2.143-156.

Soeprobowati, T. R. (2011). Variabilitas keanekaraganan dan distribusi vertikal diatom Danau Rawa Pening. Jurnal Sains dan Matematika, 19(3), 65-70.

Soeprobowati, T. R. (2012). Mitigasi danau eutrofik: studi kasus Danau Rawapening. In Prosiding Seminar Nasional Limnologi IV.

Soeprobowati, T. R. (2015). Integrated lake basin management for save Indonesian lake movement. Procedia Environmental Sciences, 23, 368-374. doi:10.1016/j.proenv.2015.01.053.

Subanti, S. (2015). Pengukuran kontribusi terhadap nilai ekonomi obyek wisata kawasan rawa pening Kabupaten Semarang dengan pendekatan multiplier effect. Seminar Nasional Matematika dan Pendidikan Matematika 2015 (pp. 519-530). Yogyakarta.

Sudarsono, S., Fitriadi, F., \& Nurjanana, N. (2018). Analisis sektor ekonomi basis dan non basis. Jurnal Ilmu Ekonomi Mulawarman (JIEM), 2(4). doi:10.29264/jiem.v2i4.2469.

Suhartono, S. (2011). Struktur ekonomi, kesempatan kerja dan ketimpangan pendapatan di Provinsi Jawa Tengah. Jurnal Organisasi dan Manajemen, 72), 86-101.

Susanto, H. (2014). Kajian komoditas unggulan, andalan dan potensial di Kabupaten Grobogan. Journal of Rural and Development, 5(1), 63-80.

Tarigan, R. (2004). Perencanaan pembangunan wilayah. Jakarta: Bumi Aksara.

Tiebout, C. M. (1956). Charles M. Tiebout. Journal of Political Economy, 64, 416-424.

Yusroni, N., \& Chadhiq, U. (2008). Analisis pemerataan pendapatan antar wilayah kecamatan di Kabupaten Semarang. AKSES: Jurnal Ekonomi dan Bisnis, 3(6), 162-172. doi:10.31942/akses.v3i6.508. 